OPEN ACCESS

Edited by:

Radomira Vankova, Academy of Sciences of the Czech

Republic, Czechia

Reviewed by: Sandeep Sharma,

Council of Scientific and Industrial

Research (CSIR), India

Santiago Signorelli,

Universidad de la República, Uruguay

*Correspondence:

László Szabados

szabados.laszlo@brc.hu

tThese authors have contributed equally to this work

Specialty section:

This article was submitted to Plant Abiotic Stress, a section of the journal

Frontiers in Plant Science

Received: 30 October 2018 Accepted: 12 November 2019 Published: 10 December 2019

Citation:

Kovács H, Aleksza D, Baba Al, Hajdu A, Király AM, Zsigmond L, Tóth SZ, Kozma-Bognár L and Szabados L (2019) Light Control of Salt-Induced Proline Accumulation Is Mediated by ELONGATED HYPOCOTYL 5 in Arabidopsis.

Front. Plant Sci. 10:1584. doi: 10.3389/fp/s.2019.01584

\section{Light Control of Salt-Induced} Proline Accumulation Is Mediated by ELONGATED HYPOCOTYL 5 in Arabidopsis

\author{
Hajnalka Kovács ${ }^{1 \dagger}$, Dávid Aleksza ${ }^{1 \dagger}$, Abu Imran Baba ${ }^{1}$, Anita Hajdu ${ }^{1}$, Anna Mária Király ${ }^{1}$, \\ Laura Zsigmond ${ }^{1}$, Szilvia Z. Tóth ${ }^{1}$, László Kozma-Bognár ${ }^{1,2}$ and László Szabados ${ }^{1 *}$ \\ ${ }^{1}$ Institute of Plant Biology, Biological Research Centre, Szeged, Hungary, ${ }^{2}$ Department of Genetics, Faculty of Sciences and \\ Informatics, University of Szeged, Szeged, Hungary
}

Plants have to adapt their metabolism to constantly changing environmental conditions, among which the availability of light and water is crucial in determining growth and development. Proline accumulation is one of the sensitive metabolic responses to extreme conditions; it is triggered by salinity or drought and is regulated by light. Here we show that red and blue but not far-red light is essential for salt-induced proline accumulation, upregulation of $\triangle 1$-PYRROLINE-5-CARBOXYLATE SYNTHASE 1 (P5CS1) and downregulation of PROLINE DEHYDROGENASE 1 (PDH1) genes, which control proline biosynthetic and catabolic pathways, respectively. Chromatin immunoprecipitation and electrophoretic mobility shift assays demonstrated that the transcription factor ELONGATED HYPOCOTYL 5 (HY5) binds to G-box and C-box elements of P5CS1 and a C-box motif of $P D H 1$. Salt-induced proline accumulation and P5CS1 expression were reduced in the hy5hyh double mutant, suggesting that HY5 promotes proline biosynthesis through connecting light and stress signals. Our results improve our understanding on interactions between stress and light signals, confirming HY5 as a key regulator in proline metabolism.

\footnotetext{
Keywords: ELONGATED HYPOCOTYL 5, proline accumulation, Arabidopsis, light signalling, gene expression regulation
}

\section{INTRODUCTION}

Proline accumulates to high levels in plants at low water potential caused by drought, salinity and in response to several other abiotic and biotic stresses (Kemble and Macpherson, 1954; Schat et al., 1997; Fabro et al., 2004; Yang et al., 2009; Szabados and Savoure, 2010; Aleksza et al., 2017). Proline was suggested to act as osmoprotectant stabilizing enzymes or maintaining redox equilibrium in adverse conditions (Delauney and Verma, 1993; Székely et al., 2008; Szabados and Savoure, 2010; Verslues and Sharma, 2010; Kavi Kishor and Sreenivasulu, 2014; Per et al., 2017). Free proline content is defined by biosynthesis and degradation, and modulated by transport, protein synthesis, and degradation (Lehmann et al., 2010; Verslues and Sharma, 2010; Hildebrandt, 2018). The main biosynthetic pathway has two consecutive steps catalyzed by the rate-limiting $\Delta^{1}$-pyrroline-carboxylate synthetase (P5CS) enzyme (Hu et al., 1992) followed by P5C reductase (P5CR) (Delauney and Verma, 1990). Proline biosynthesis takes place in cytosol, although localization of P5CS1-GFP protein 
in chloroplasts of salt-treated cells suggest that biosynthesis may take place in plastids under stress conditions (Székely et al., 2008). Proline degradation is a mitochondrial oxidative process, mediated by the rate-limiting proline dehydrogenase $(\mathrm{PDH})$ and $\mathrm{P} 5 \mathrm{C}$ dehydrogenase $(\mathrm{P} 5 \mathrm{CDH})$ enzymes (Kiyosue et al., 1996; Servet et al., 2012). In most plants P5CS is encoded by two genes. In Arabidopsis P5CS1 (AT2G39800) responds to hyperosmotic stress and is regulated by ABA-dependent and independent signals, whereas P5CS2 (AT3G55610) is considered to be a housekeeping gene, which can be induced by certain pathogens via salicylic acid-dependent signals (Savouré et al., 1997; Strizhov et al., 1997; Fabro et al., 2004; Székely et al., 2008; Sharma and Verslues, 2010). PDH1 (AT3G30775) is repressed in high osmotic conditions and is induced by proline during stress recovery (Kiyosue et al., 1996). Compared to $P D H 1, P D H 2$ has a very low expression level, which is however induced during phosphate starvation (Aleksza et al., 2017). ABA, reactive oxygen species, calcium, and lipid signals were implicated in the regulation of proline metabolism (Thiery et al., 2004; Parre et al., 2007; Ben Rejeb et al., 2015). Although important progress has been made in the last few years, transcription regulation of key genes in proline metabolism is far from well understood. A number of cis regulatory sequences have been identified in promoters or 5'UTRs of key metabolic genes, but direct evidence on promoter-binding transcription factors and their function is scarce (Fichman et al., 2015; Zarattini and Forlani, 2017). We have recently described that PHOSPHATE STARVATION RESPONSE 1 (PHR1) and PHOSPHATE STARVATION RESPONSE LIKE-1 (PHL1) transcription factors bind the P1BS motif in the first intron of P5CS1, upregulate its expression, and promote proline accumulation during phosphate starvation (Aleksza et al., 2017). A recent report showed that the transcription factor ANAC55 (Arabidopsis NAM, ATAF, and CUC) is a positive regulator of P5CS1 expression and proline accumulation in high osmotic conditions, although direct binding to P5CS1 promoter elements was not demonstrated (Fu et al., 2018). Allelic variation in the barley P5CS1 gene was recently reported, showing that promoter mutations in the abscisic acid-responsive element (ABRE) can considerably alter P5CS1 expression, proline accumulation, and drought tolerance (Muzammil et al., 2018). Some information is available on transcriptional regulation of $P D H 1$. Basic leucine zipper (bZIP) transcription factors of the ATB2 subgroup were shown to upregulate $P D H 1$ expression during hypoosmolarity through binding to the ACTCAT cis-acting promoter element (Satoh et al., 2002; Satoh et al., 2004; Weltmeier et al., 2006). Chromatin immunoprecipitation (ChIP) analysis confirmed that bZIP1 and bZIP53 factors bind to the PDH1 promoter and upregulate it in low energy conditions (Dietrich et al., 2011). Besides transcriptional control, epigenetic regulation and alternative splicing were shown to influence the expression of the P5CS1 and PDH1 genes (Kesari et al., 2012; Jimenez-Arias et al., 2015). Histone methylation was recently shown to control stress memory response of P5CS1 in Arabidopsis (Feng et al., 2016).

Light was found to influence proline levels by inducing P5CS1 and repressing PDH1 expression (Hayashi et al., 2000; Abraham et al., 2003; Diaz et al., 2005). While considered as a housekeeping gene, P5CS2 was identified as a target of CONSTANS (CO) and is therefore also subject to light and flowering time regulation (Samach et al., 2000). Datamining of publicly available transcript profiling data (Dubois et al., 2017) suggested reciprocal fluctuation of the expression of the P5CS1 and PDH1 genes in response to light and drought (Figure S1).

Light can influence gene expression in various ways. Light perception through photoreceptors is mediated by phytochromes (PHYA-E) absorbing red/far-red light, cryptochromes (CRY12) sensing blue light and phototropins (PHOT1-2), which absorb blue and additionally UV-A light (Briggs and Christie, 2002; Franklin and Quail, 2010; Kami et al., 2010; Chaves et al., 2011). bHLH-type phytochrome-interacting factors repress photomorphogenic development and promote the expression of light-repressed genes, but are degraded upon interaction with the active forms of phytochrome receptors (Leivar and Monte, 2014). The bZIP-type transcription factor ELONGATED HYPOCOTYL 5 (HY5) is a phytochrome-interacting factor antagonist that acts downstream of virtually all classes of photoreceptors, and promotes photomorphogenesis and the expression of lightinduced genes (Cluis et al., 2004; Toledo-Ortiz et al., 2014). Crosstalk between light and several other signaling pathways has been demonstrated, in which HY5 can function as a signaling hub. HY5 directly interacts with ACGT-containing (ACE) LightResponsive Elements in the promoters of light-induced genes and upregulates their transcription (Chattopadhyay et al., 1998). Signals from photoreceptors promote accumulation of HY5 at transcriptional and posttranscriptional levels (Binkert et al., 2014; Sheerin et al., 2015), but apparently do not affect the DNAbinding affinity or specificity of the HY5 protein (Hajdu et al., 2018). HY5 lacks any domains with transcriptional regulator function, thus it requires co-factors to control gene expression ( $\mathrm{Li}$ et al., 2010) and is supposed to act as a component of multiprotein complexes. More recently the role of HY5 in multiple signaling systems was uncovered, showing that, together with the closely related HY5-HOMOLOG $(\mathrm{HYH})$ factor, it integrates light, hormonal, and developmental regulation through multiple interactions with other transcription factors and regulatory proteins (Gangappa and Botto, 2016). A recent paper described that the stress-induced transcription memory of P5CS1 is influenced by light and is mediated by HY5, able to bind to C/A-box sequence elements in the P5CS1 promoter and 5' UTR region (Feng et al., 2016). HY5 was also shown to modulate ABA signaling by promoting $A B I 5$ expression through binding to its promoter (Chen et al., 2008). Light and ABA regulation is influenced by the $\mathrm{C} 2 \mathrm{H} 2$-type zinc finger protein $\mathrm{ZFP} 3$, which represses ABA signals and promotes photomorphogenesis (Joseph et al., 2014). Responses to light signals can be finetuned by the EREBP-type ABI4 which is implicated in ABA and sugar signaling (Wind et al., 2012). Interacting light, ABA and stress signals are therefore influenced by different sets of transcription factors such as the bZIP-type HY5 and ABI5, the C2H2-type ZFP3, or the EREBP-type ABI4.

In addition to perception through photoreceptors, light also affects the expression of a set of nuclear genes by chloroplast retrograde signaling which depends on light reactions of photosynthesis (Gollan et al., 2015). In this regulatory system chloroplasts acts as sensors and signaling components include 
sugar and carotenoid metabolites, reactive oxygen species, plastoquinone pool redox state, and various classes of regulatory proteins such as protein kinases and transcription factors. Chloroplast-derived signals control chloroplast development and responses to environmetal stresses (Fey et al., 2005; Fernandez and Strand, 2008; Gollan et al., 2015; Kleine and Leister, 2016; D'Alessandro et al., 2018).

This communication focuses on the light-dependent control of proline metabolism. We show that HY5 binds to conserved sequence elements of the P5CS1 and PDH1 genes and can positively contribute to salt-induced proline accumulation. HY5 seems to function as a regulatory hub that integrates light and stress signals in the control of proline metabolism. We conclude that proline metabolism is controlled by multiple regulatory pathways and is influenced by interacting stress and light signals.

\section{RESULTS}

\section{Proline Accumulation Is Influenced by Light}

To characterize light-dependent proline accumulation in Arabidopsis, an in vitro experimental system was designed: Fourteen-day-old plantlets were treated with high intensity light $\left(550 \mu \mathrm{E} \mathrm{m}^{-2} \mathrm{~s}^{-1}\right)$ or deprived of light for up to 5 days, and subsequently salt or ABA-triggered proline accumulation was monitored periodically (Figure 1A). When plants were irradiated with strong light for several days, proline levels accumulated up to three times higher as compared to plants kept under standard light conditions (Figure 1B). Proline accumulation was compromised in the p5cs1-1 mutant (Székely et al., 2008), suggesting that the P5CS1 gene controls the rate-limiting step in proline accumulation in these conditions. In standard light conditions 1-day $10 \mu \mathrm{M}$ ABA and $150 \mathrm{mM} \mathrm{NaCl}$ treatments lead to two or five times higher proline contents, respectively. When plants were deprived of light, proline accumulation was considerably smaller: 1 day of dark adaptation reduced proline levels from $40 \%$ to $60 \%$ of light cultured plants, whereas 5 days in darkness prevented the enhancement of proline content (Figure 1C). The negative effect of dark on proline accumulation may derive from the lack of adequate light or photoreceptor-derived signals reducing proline biosynthesis and/or inducing catabolism. Alternatively, if energy shortage prevents proline accumulation in dark, then externally added sugar should compensate for the absence of light. To test energy dependence, proline concentrations were measured in dark-adapted plants in the presence of various concentrations of sucrose. Proline contents in dark-adapted plants were similar in the presence of $0 \%$ and $2 \%(\mathrm{~W} / \mathrm{V})$ sucrose in the culture medium, whereas $4 \%(\mathrm{~W} / \mathrm{V})$ sucrose significantly enhanced proline accumulation. Proline levels in these conditions were, however, still far inferior to those in illuminated plants, which accumulated five to ten times more proline (Figure 1D). When proline content was compared in plants treated with sucrose, glucose, or mannitol, only minor differences were observed (Figure S2). These results suggest that sugar-dependent glycolysis cannot

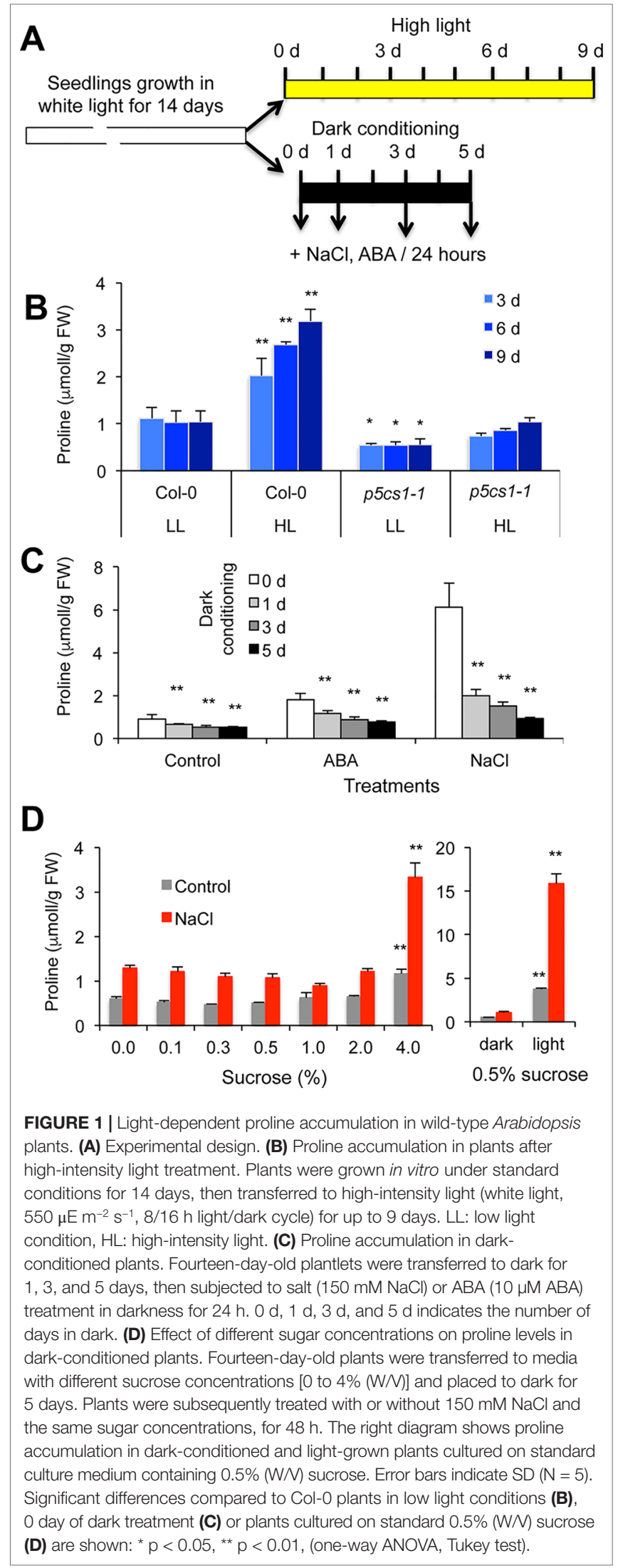


compensate for the lack of light signals or other photosynthesisderived metabolites such as NADPH.

Light generates specific signals, which can trigger biosynthetic and/or repress catabolic pathways. Light signals are perceived by specific photoreceptors, each of them possessing well-defined sensitivity to a particular spectrum of light (Franklin and Quail, 2010; Chaves et al., 2011). To test the effect of light quality on proline metabolism, dark-conditioned plants were transferred to white or monochromatic red, far-red or blue lights with or without simultaneous salt stress (Figure 2A). The light intensities for each light qualities (white light: fluorescent cool white, 4200 $\mathrm{K}, 60 \mu \mathrm{E} \mathrm{m}^{-2} \mathrm{~s}^{-1}$, monochromatic blue: $470 \mathrm{~nm}, 15 \mu \mathrm{E} \mathrm{m}^{-2} \mathrm{~s}^{-1}$, red: $660 \mathrm{~nm}, 15 \mu \mathrm{E} \mathrm{m}^{-2} \mathrm{~s}^{-1}$, or far-red: $730 \mathrm{~nm}, 5 \mu \mathrm{E} \mathrm{m}^{-2} \mathrm{~s}^{-1}$ light), were sufficient to saturate photoreceptors and light signaling cascades but not the photosynthetic electron transport (Wolf et al., 2011; Adam et al., 2013). In the absence of salt stress, proline levels increased under white, red and blue light, but remained unchanged in darkness or under far-red light (Figure 2B). Proline concentrations increased more than 10-fold in salttreated plants under white or red light, whereas under blue light 5 -fold enhancement was measured. Salt stress could only slightly augment free proline content in plants kept in dark or illuminated by monochromatic far-red light (Figure 2B). The effect of white and monochromatic light on proline accumulation was similar in Columbia 0 (Col-0) and Wassilewskija (WS) ecotypes (Figure S3). These results suggest that to promote proline accumulation, red is the most efficient component of the light spectrum followed by blue, whereas far-red light is insufficient.

To investigate the molecular background of light-dependent proline accumulation, expression patterns of the key metabolic genes P5CS1 and PDH1 were monitored under different light regimes with or without salt treatment. Transcript levels of P5CS1 were significantly higher in plants illuminated with white, red, and blue light than in plants kept in dark or illuminated by far-red light. Salt treatment enhanced P5CS1 expression in all light conditions, and transcript levels were highest under white and red lights followed by blue, but were moderately enhanced in far-red light or in darkness (Figure 2C, Figure S4). PDH1 expression was downregulated by white, red, and blue light and not affected significantly under far-red light. Salt treatment repressed PDH1 expression even more in most light conditions, including in darkness (Figure 2C, Figure S4). These results suggest that besides white light, red, and blue monochromatic lights are efficient in promoting P5CS1 and suppressing PDH1 expression, which ultimately leads to high levels of proline accumulation when plants are exposed to salt stress.

In order to investigate whether photosynthetic electron transport is required for proline accumulation, leaves were treated with 3-(3',4'-dichlorophenyl)-1,1-dimethylurea (DCMU) in combination with salt (Figure S5). DCMU binds irreversibly to the acceptor side of photosystem II thereby inhibiting linear electron transport, which results in altered fast chlorophyll $a$ fluorescence (OJIP) kinetics. Upon full inhibition, the $J\left(\mathrm{~F}_{2 \mathrm{~ms}}\right)$ step equals the maximum fluorescence $\left(\mathrm{F}_{\mathrm{M}}\right.$ or $\left.\mathrm{P}\right)$ intensity (Tóth et al., 2007), as seen also in Figure S5C. The DCMU treatment alone had no effect on proline levels, whereas $\mathrm{NaCl}$-induced

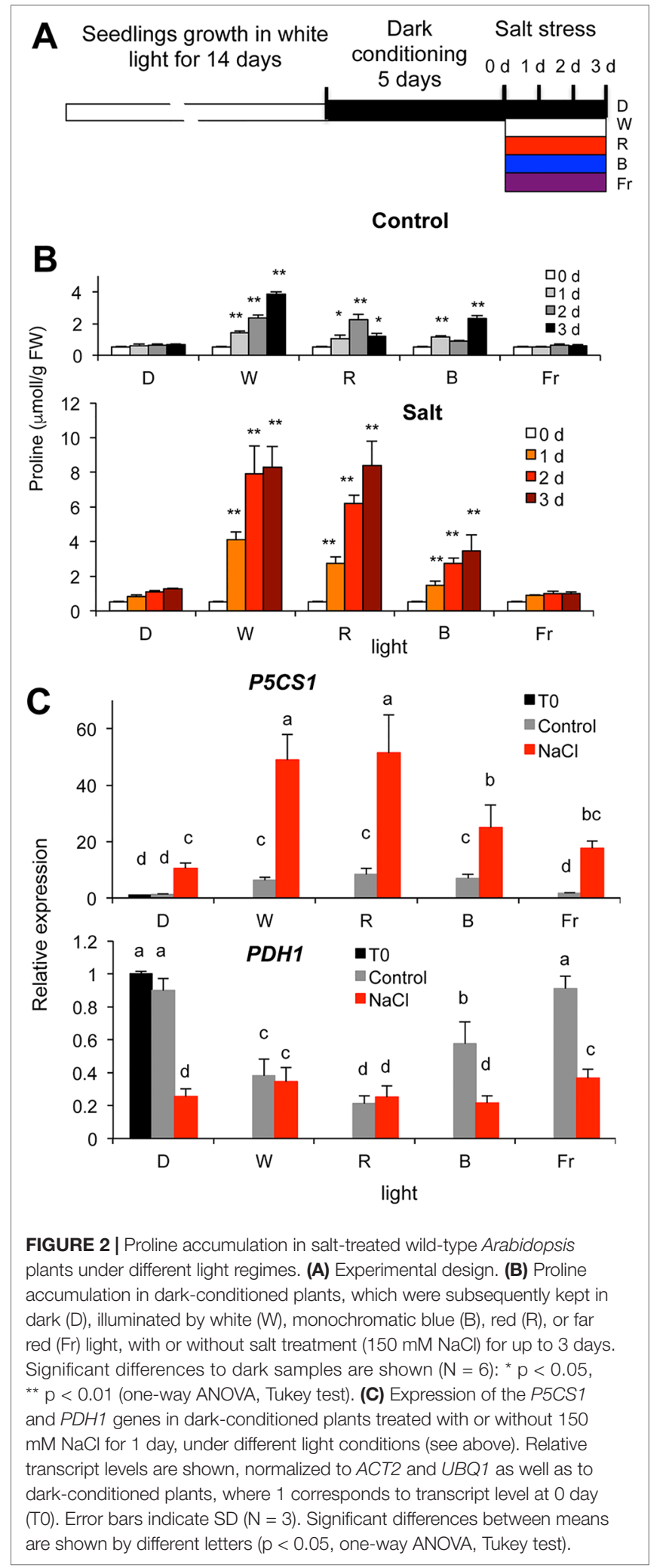

proline accumulation was significantly reduced (Figure S5A). In the presence of DCMU P5CS1 induction was slightly reduced in salt-treated plants, whereas $P D H 1$ was upregulated in both salttreated and control plants (Figure S5B). 


\section{HY5 Binds to Promoter Elements of the P5CS1 and PDH1 Genes}

The bZIP-type transcription factor HY5 is a key positive regulator of light-dependent gene expression that controls transcription of thousands of light-induced genes (Cluis et al., 2004; Toledo-Ortiz et al., 2014). A recent ChIP-seq analysis of HY5 binding sites revealed that this transcription factor recognizes conserved cisacting elements in more than three thousand genes, both under red and blue light (Hajdu et al., 2018). Genome-wide mapping of HY5 binding sites revealed that this TF can recognize the promoter regions of the $P 5 C S 1$ and $P D H 1$ genes (Figures S6, S7). While peak of the reads were mapped close to the transcription initiation site of P5CS1, maximum reads were localized to 0.5 $\mathrm{kb}$ upstream of the $\mathrm{PDH} 1$ transcription initiation site. Another recent study revealed binding of HY5 to the $5^{\prime}$ UTR and a distal upstream region of P5CS1 (Feng et al., 2016). Promoter and 5' UTR regions of P5CS1 contain a number of predicted regulatory sequence motifs, including a G-box (CACGTG) at +172 bp in the $5^{\prime}$ UTR and a C-box (GACGTC) in the promoter, at -59 bp distance from the transcription start site, which can serve as binding sites of HY5 (Figure 3A) (Fichman et al., 2015). The PDH1 promoter contains one conserved C-box motif in the promoter, at $-553 \mathrm{bp}$ distance from the transcription start site (Figure 3A).

To verify HY5 binding in the identified regulatory regions, ChIP followed by quantitative PCR (ChIP-qPCR) assays were performed on P5CS1 and PDH1 promoter fragments containing the predicted G-box and C-box sequence motifs. When compared to intergenic regions, specific enrichment in qPCR-amplified C-box- and G-box-containing P5CS1 and PDH1 promoter fragments was detected in the HY5-YFPimmunoprecipitated DNA samples (Figure 3B). Enrichment of HY5 binding to P5CS1 G-box and C-box regions was around 14 to 16 times higher while it was 5 times higher on $\mathrm{C}$-box region of the $P D H 1$ promoter than on a control intergenic region (Figure 3B). ChIP-qPCR experiments therefore confirmed that HY5 interacts in vivo with the selected $5^{\prime}$ UTR and promoter regions of both the P5CS1 and the PDH1 genes. To compare our results with previously reported HY5 assays, ChIP assay was performed with primers used to amplify Region 2 and Region 5 of P5CS1, as defined by Feng et al. (2016). Region 2 is a 140 bp fragment, in the $5^{\prime}$ UTR (from -5 to +135 bp), flanked by C-box and G-box sequences. Region 5 is a $147 \mathrm{bp}$ fragment in the upstream region (from -2129 to $-2276 \mathrm{bp}$ ), which corresponds the previously described "Essential for Memory Fragment" (EMF) (Feng et al., 2016). In our experimental conditions enrichment of Region 2 in ChIP assay was similar to fragments containing G-box and C-box elements, whereas enrichment was a magnitude lower when HY5 binding was tested for Region 5, corresponding to EMF (Figure 3B).

To verify that the conserved C-box and G-box motifs are indeed the targets of HY5, electrophoretic mobility shift assays (EMSA) were performed using $56 \mathrm{bp}$ dsDNA fragments containing the native regulatory sequences or their mutated forms in which the conserved CACGTG or GACGTC sequence motifs were altered, eliminating the core ACGT sequence (Figure 4A). Complex formation of HY5 with ds oligonucleotides corresponding to wild-type $P 5 C S 1$ and $P D H 1$ promoter fragments was observed in the EMSA assays. Complexes between HY5 and oligoes carrying the mutated G-box or C-box sequences were, however, not formed or were detected at much lower level (Figure 4B). These experiments confirmed that the C-box and G-box sequences are indeed responsible for HY5 binding to the P5CS1 promoter ( -59 bp) or the $5^{\prime}$ UTR (+172 bp) regions as well as binding of the $P D H 1$ promoter ( $-553 \mathrm{bp}$ ) region.

\section{HY5 Regulates Proline Accumulation and Expression of the P5CS1 and PDH1 Genes}

To study the function of HY5 in proline metabolism, free proline contents and transcript levels of P5CS1 and PDH1 genes were compared in wild-type (WS) and hy5hyh mutant plants carrying knockout mutations for both HY5 and the closely related $H Y H$ genes (Hajdu et al., 2018). Wild-type and hy5hyh double mutant plants were conditioned to dark as described above, and were subsequently treated by salt under white and monochromatic red or blue light (Figure 5A). Compared to plants kept in darkness, proline levels were enhanced by illumination with both white and red or blue monochromatic lights. When compared to wild type, proline levels were not affected or were slightly lower in illuminated hy5hyh mutants without salt treatment (Figures 5B, S8). Salt stress enhanced proline contents three to six times in illuminated plants, while proline accumulation was around 50\% lower in the hy5hyh mutant when compared to wild-type plants in the same conditions (Figures 5B, S8). When plants were kept in darkness, proline levels were only slightly increased by salt treatment, and enhancement was similar in both genotypes.

P5CS1 transcript levels were low in both wild-type and hy5hyh mutants without salt treatment with minor induction by illumination. P5CS1 expression was clearly induced by $6 \mathrm{~h}$ of salt treatment in illuminated plants, reaching approximately $50 \%$ lower transcripts in the hy5hyh mutant than in wild-type plants (Figures 5C, S9B). In all light conditions transcript levels were higher after $6 \mathrm{~h}$ of stress than after $24 \mathrm{~h}$ (Figure 5C). $P D H 1$ expression was reduced by illumination and by salt stress in all light conditions. Genotype-dependent differences in $\mathrm{PDH} 1$ transcript levels were however less pronounced and downregulation was more variable (Figures 5D, S9C). The P5CS1 transcription pattern positively correlated with changes in proline levels, indicating that biosynthesis is essential in defining proline accumulation in these conditions, while $\mathrm{PDH} 1$ controlled catabolism can fine-tune proline levels. These data indicate that HY5 (and possibly $\mathrm{HYH}$ ) is a positive regulator of proline accumulation by contributing to the expression of the P5CS1 gene with a minor role in the control of $P D H 1$ expression.

\section{DISCUSSION}

In this study we investigated the importance of light in saltdependent proline accumulation, focusing on HY5-mediated light signals. A model summarizes our results integrating it with previous studies (Figure 6). Light was previously shown to 


\section{A}
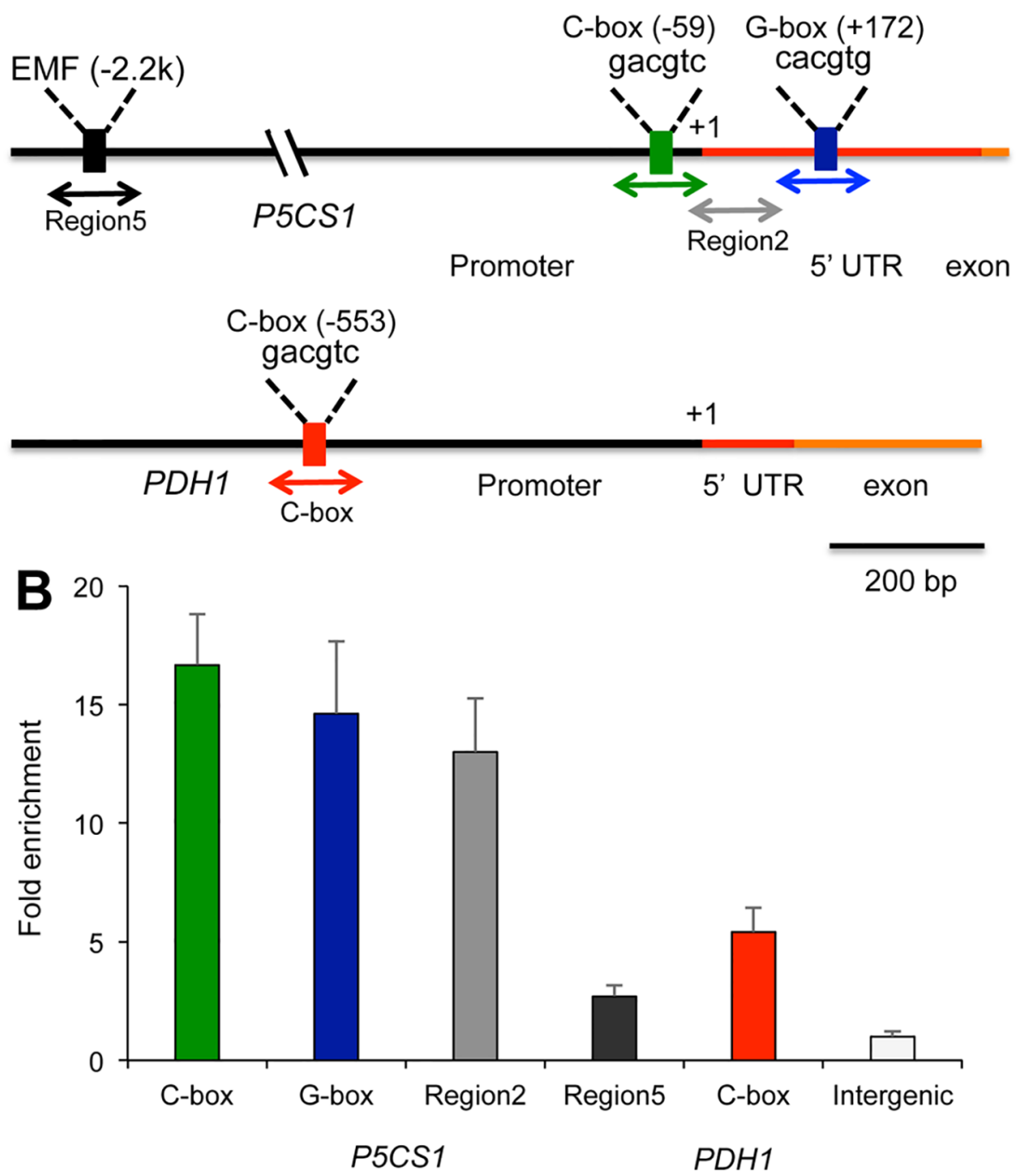

FIGURE 3 | Binding of HY5 on promoter regions of the P5CS1 and PDH1 genes. (A) Schematic structure of the P5CS1 and PDH1 promoters indicating the positions of conserved $\mathrm{G}$ and $\mathrm{C}$ box elements and Region 2 and Region 5, according to (Feng et al., 2016). Color code: black line: promoter, red line: 5'UTR region, yellow line: exon. Boxes indicate the positions of predicted basic leucine zipper (bZIP) binding sites: black: "Essential for Memory Fragment" (EMF) (Feng et al., 2016), green: C-box, blue: G-box (P5CS1 promoter), red box on PDH1 promoter indicate C-box (AthaMap, http://www.athamap.de). Positions indicate distance from transcription start site (+1). Double arrows indicate the regions amplified by quantitative PCR (qPCR) after chromatin immunoprecipitation. (B) Result of chromatin immunoprecipitation followed by quantitative PCR (ChIP-qPCR) tests on two P5CS1 and one PDH1 promoter region. An intergenic region with no C or G-box sequences was used as reference (=1). Error bars on diagrams indicate $\mathrm{SD}(\mathrm{N}=3)$.

promote proline accumulation and inversely influence P5CS1 and PDH1 expression in Arabidopsis plants (Figure S1, Hayashi et al., 2000; Abraham et al., 2003). Here we showed that high light enhances, while extended darkness reduces proline levels, and absence of light cannot be compensated by externally supplied sugar as energy source (Figures 1, S2). Proline metabolism in Arabidopsis was found to be controlled by red and blue lights but is less influenced by far red light (Figures 2, S3). We showed that light-dependent proline accumulation is regulated by HY5, a key bZIP-type transcription factor in light signaling which is known to be a positive regulator of photomorphogenesis (Figures 5, S8, S9,
Holm et al., 2002; Toledo-Ortiz et al., 2014). Genome-wide ChIPchip or ChIP-seq experiments revealed that HY5 directly controls around $10 \%$ of the Arabidopsis genes through binding to their promoters (Lee et al., 2007; Zhang et al., 2011; Hajdu et al., 2018). Datamining of the ChIP-seq supplementary datasets revealed that HY5 recognizes the $5^{\prime}$ regions of the $P 5 C S 1$ and $P D H 1$ genes, suggesting that these genes are direct targets of this bZIP factor (Hajdu et al., 2018) (Figures S6, S7). HY5 was found to bind directly to the promoter or 5' UTR regions of the key metabolic genes P5CS1 and PDH1, which modulate rate-limiting steps in proline biosynthesis and degradation. The $5^{\prime}$ regulatory region 


\section{A}

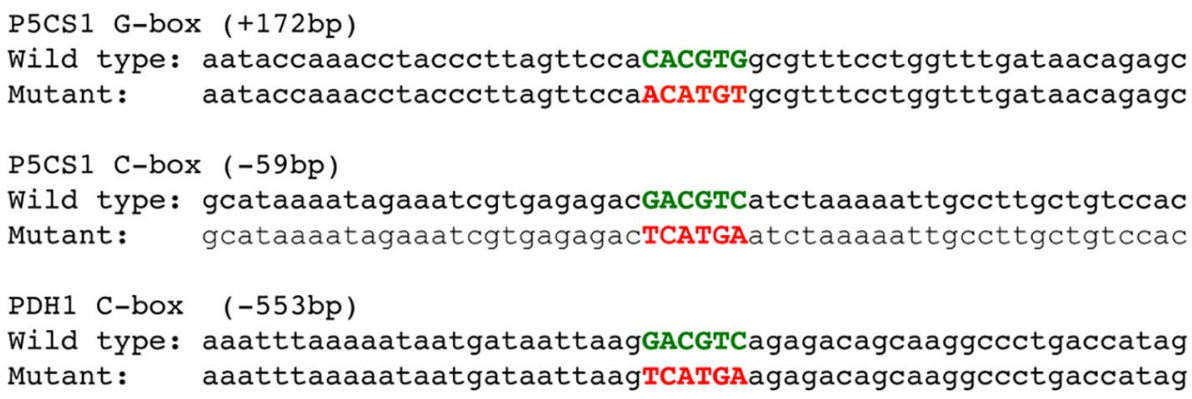

B

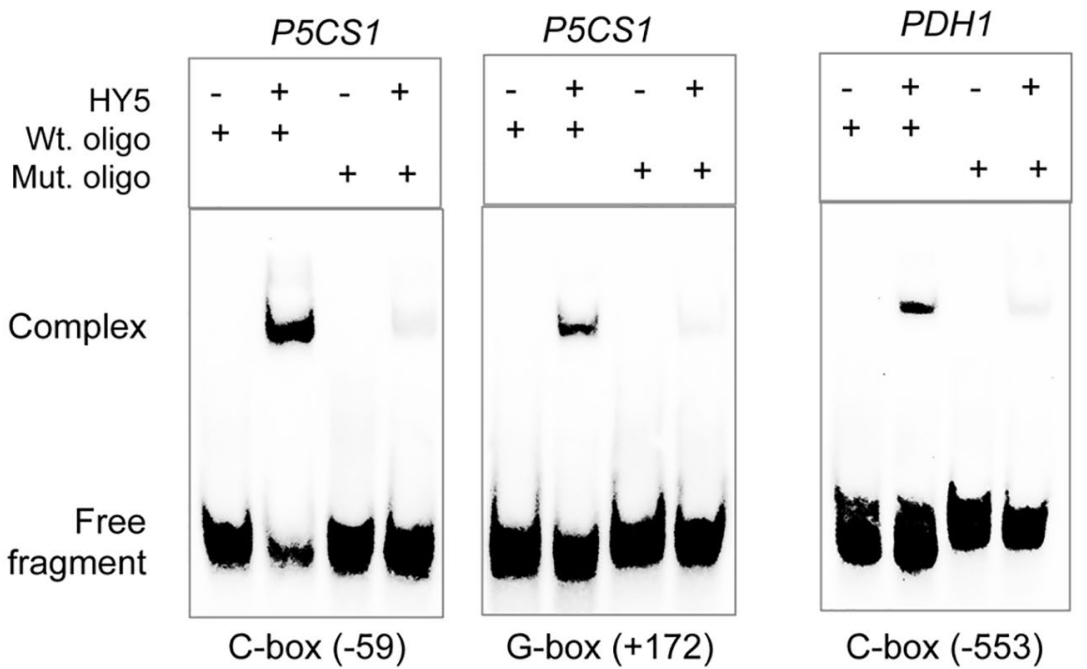

FIGURE 4 | Confirmation of TF binding sequence motifs with electrophoretic mobility assay (EMSA). (A) Sequences of the oligonucleotides containing wild-type and mutated G-box and C-box sequences of the P5CS1 and PDH1 promoters. (B) EMSA assays with wild-type (Wt. oligo) and mutant (Mut. oligo) double stranded oligonucleotides and purified HY5 protein. Note complex formation of HY5 protein with wild-type oligonucleotides, which is almost invisible with mutant ones with altered ACGT core sequences.

of P5CS1 contains various cis-regulatory elements including a well-defined G-box in the 5'UTR region and a C-box motif in the promoter, which are conserved in P5CS1 promoters of closelyrelated Brassicaceae species (Fichman et al., 2015). Sequence analysis revealed one C-box motif in the $P D H 1$ promoter. ChIPqPCR experiments demonstrated in vivo binding of $\mathrm{HY} 5$ to at least three promoter regions of $P 5 C S 1$, and one region of $P D H 1$, which contained G-box or C-box sequence elements (Figure 3). EMSA experiments demonstrated that HY5 can directly and specifically bind to these sequence motifs in vitro (Figure 4). Promoter binding therefore strongly suggest that HY5 is directly involved in the control of P5CS1 and PDH1 transcription. G-box and C-box sequence motifs have an ACGT core, which is essential for binding of bZIP transcription factors, whereas nucleotides flanking the core sequence define the specificity of sequence recognition (Williams et al., 1992; Izawa et al., 1993). Mutations eliminating the ACGT core in the P5CS1 and PDH1 G-box and C-box motifs weakened or abolished HY5 binding to these DNA fragments, confirming that these promoter elements are indeed critical for the complex formation with this transcription factor (Figure 4). ACGT-containing sequence motifs are present in ABA Response Elements (ABRE), binding sites of bZIP-type $\mathrm{AREB} / \mathrm{ABF}$ type transcription factors, which are key regulators of ABA-induced gene activation (Hobo et al., 1999; Fujita et al., 2005; Yoshida et al., 2010). Polymorphism in ABRE or adjacent CE motifs were recently shown to influence P5CS1 expression and proline accumulation in barley, although TF binding to these motifs was not reported (Muzammil et al., 2018).

Two other HY5 binding regions were previously identified in the Arabidopsis P5CS1 promoter, which were implicated in maintaining stress memory (Feng et al., 2016). Enhanced H3K4me3 levels near the P5CS1 transcription start site were associated with light exposure and shown to correlate with transcript levels in repeated stresses. The distal EMF (Region 5 in Figure 3) is located $2.2 \mathrm{~kb}$ upstream of the transcription start site, and contains a C/A box, which can bind HY5 (Feng et al., 2016). Region 2 is located in $5^{\prime}$ UTR, which however has no recognizable sequence element for HY5 binding, but is flanked 


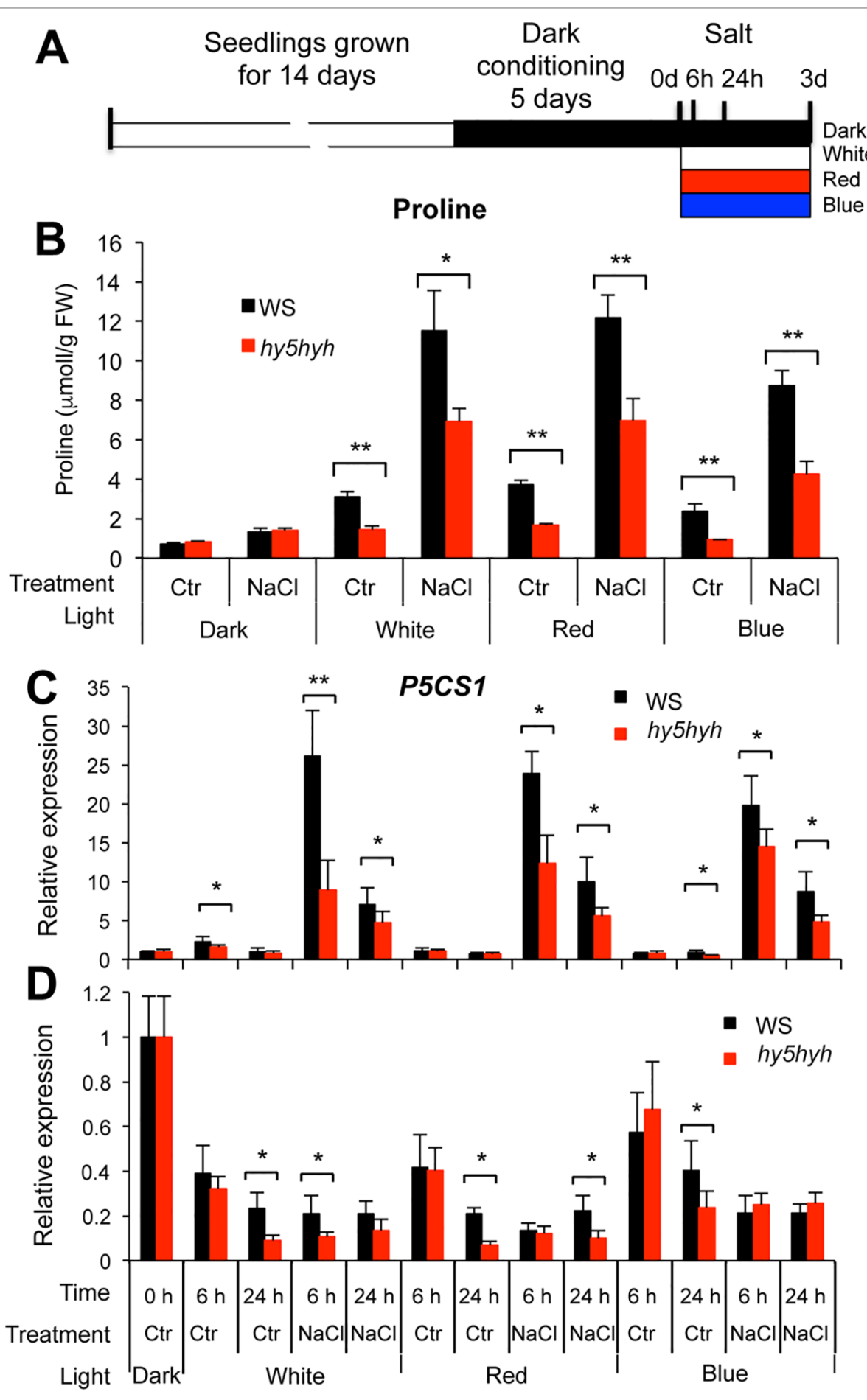

FIGURE 5 | Proline accumulation and expression of the P5CS1 and PDH1 genes in salt-treated wild-type and hy5hyh double mutant plants. (A) Experimental design: 14-day-old in vitro-grown plants were conditioned by dark treatment for 5 days and subsequently treated with or without $150 \mathrm{mM} \mathrm{NaCl}$ and illuminated with white or monochromatic red or blue light. (B) Proline accumulation in Wassilewskija (WS) wild-type and hy5hyh mutant plants after 3 days of salt treatment. Error bars indicate SD (N = 5). (C, D) Transcript levels of the P5CS1 (C) and PDH1 (D) genes after 6 and $24 \mathrm{~h}$ of salt treatment. Relative transcript levels are shown, which were normalized to $A C T 2$ and $U B Q 1$ reference genes as well as to dark-conditioned plants. Abbreviations: Ctr: control, NaCl: salt treatment. Error bars indicate $S D(N=3)$. Significant differences between wild type and mutant values are: ${ }^{\star} p<0.05,{ }^{\star \star} p<0.01$ (two-way ANOVA, Tukey test, fixed parameters were genotypes and treatments). 


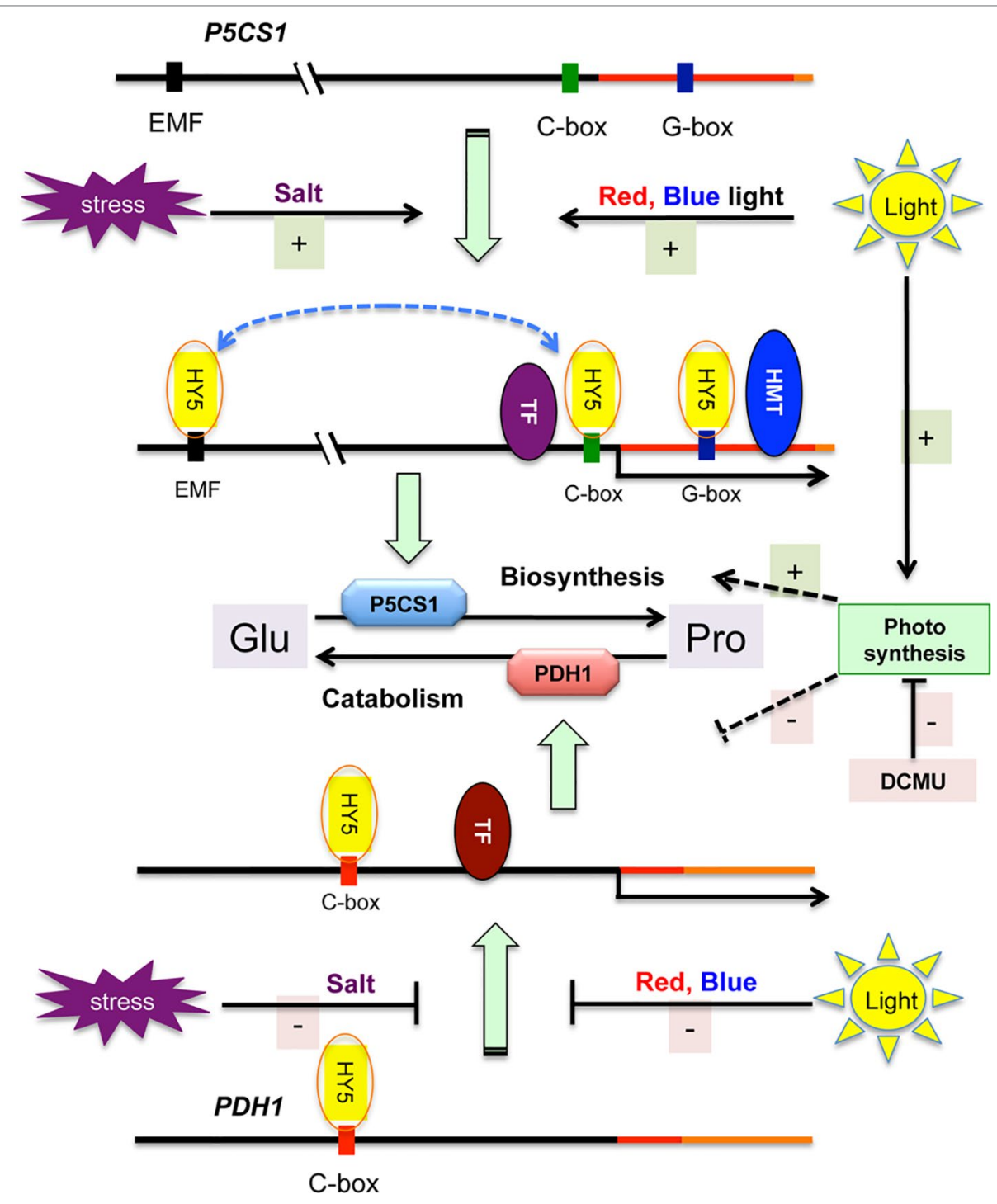

FIGURE 6 | Model of stress and light regulation of proline metabolism in Arabidopsis. Salt stress and light induces P5CS1 and inhibits PDH1 expression, promoting proline biosynthesis and reducing catabolism. Schematic maps of P5CS1 (upper line) and PDH1 (lower line) promoter and 5' UTR regions are shown. Only HY5 binding sites are indicated in the schematic maps. HMT corresponds to histone merthyltransferase and TF indicates other transcription factors which can regulate transcription of P5CS1 (Feng et al., 2016; Aleksza et al., 2017; Fu et al., 2018) or PDH1 (Satoh et al., 2004; Weltmeier et al., 2006; Dietrich et al., 2011). Lightcontrolled HY5 binds to the promoters of both genes and contributes to P5CS1 activation, but has only a minor effect on PDH1 expression. Stress conditions as well as red and blue light activate P5CS1 transcription (upper scheme), and inhibits PDH1 activation (lower segment of the scheme). Photosynthesis can promote proline accumulation (probably enhancing biosynthesis and reducing catabolism) via an unknown mechanism, which is inhibited by 3-(3', $4^{\prime}-$ dichlorophenyl)-1,1dimethylurea (DCMU). Solid lines indicate confirmed, dashed lines show unknown/predicted interaction or regulation.

by the G-box and C-box sequence motifs, reported in this study. In our ChIP-qPCR assay similar degrees of enrichments were detected for G-box, C-box motifs and Region 2 of Feng et al. (2016) (Figure 3). ChIP technology has 300 to 400 bp resolution which can cover Region 2 and the flanking G-box and C-box motifs. ChIP-qPCR with primers in Region 2 could therefore detect chromatin fragments which were immunoprecipitated by the flanking G-box or C-box elements. Similar degrees of ChIPqPCR enrichment were reported earlier for both Region 2 and Region 5 (Feng et al., 2016). In our ChIP assay binding efficiency of HY5 to Region 5 was however a magnitude lower than binding to C- or G-boxes (Figure 3). We used functional YFP-tagged HY5 and GFP-trap agarose beads for ChIP, whereas Feng et al. (2016) employed anti-HY5, which may explain the differences.

One of the key steps in the regulation of light-dependent gene expression is the photoreceptor-induced accumulation of the HY5 protein. Since this process is affected by virtually all photoreceptors, hy5 mutants show photomorphogenic phenotypes, such as elongated hypocotyls not only in blue or red, but in far-red light as well (Abbas et al., 2014). Our data demonstrated that stress-induced proline accumulation did not occur in far-red light. One possibility is that far-red-derived 
signals are insufficient for P5CS1 induction and proline accumulation during salt stress. PHYA is the sole light receptor in Arabidopsis that can be activated by far-red light (Casal et al., 2014). Although PHYA signaling promotes the accumulation of HY5, apparently alone it cannot activate P5CS1 transcription. Alternatively, low photosynthetic activity under far red light might prevent proline biosynthesis and promote catabolism via metabolic regulation (eg. due to low NAPDH pools) (Thapper et al., 2009; Pavlou et al., 2018).

Heterodimerization of bZIP transcription factors allows combinatorial control of target gene expression (Ehlert et al., 2006; Yoshida et al., 2010; Dietrich et al., 2011). HY5 and the related HYH factors were shown to form homo and heterodimers and promote light-induced expression of target genes (Holm et al., 2002). Formation of G-box-binding heteromers of HY5 with other bZIP factors was reported, suggesting that this transcription factor may cooperatively regulate transcription of ABA-induced target genes with other bZIP factors such as ABFs (Yoshida et al., 2010; Singh et al., 2012). Whether HY5 interacts with $\mathrm{ABFs}$ or other TFs on P5CS1 and/or PDH1 promoters remains to be elucidated.

The functionality of promoter binding by HY5 was tested by comparing transcript levels of the P5CS1 and PDH1 genes and proline accumulation in hy5hyh double mutant with those in wild-type plants under different light regimes (Figures 5, S8, S9). HY5 and HYH transcription factors are partially redundant, therefore the double knockout hy5hyh mutant was used in these studies. P5CS1 transcript levels were lower in the salt-treated hy5hyh double mutant, suggesting that HY5 and perhaps the closely related HYH indeed contribute to high-level P5CS1 induction in salt-stressed plants. Lower proline levels in salt-treated hy5hyh plants correlated with reduced transcript levels of P5CS1. Expression of PDH1 was less influenced in the hy5hyh mutant, although minor differences could be detected during illumination with monochromatic light. These results confirm the positive role of HY5 in proline accumulation, which mediates light signals and modulates transcriptional activities of key metabolic genes. Complex formation of HY5 with the distal EMF region (Feng et al., 2016) and 5' UTR sequences of P5CS1 promoter was required for the retention of $\mathrm{H} 3 \mathrm{~K} 4 \mathrm{me} 3$ levels and the maintenance of stress memory (Feng et al., 2016). HY5 seems to functions as a regulatory hub, which transmits light signals and connects them to stress and/or ABA signals and histone methylation and regulates the transcription of key metabolic genes by directly binding to conserved cis regulatory elements of their promoters (Figure 6).

In addition to photoreceptor-mediated signaling, light may modulate proline biosynthesis in other ways. Light can provide energy and reducing agents such as NADPH through photosynthesis, and light can modulate gene expression by specific signals, such as the redox state of the plastoquinone pool. The decline of proline levels in darkness could not be compensated by externally added sugars, suggesting that energy limitation is not a principal reason of light dependency (Figures 1, S2). Inhibition of photosynthetic electron transport with DCMU, however, reduced salt-dependent proline accumulation, $P 5 C S 1$ activation, and considerably promoted $P D H 1$ expression, demonstrating that photosynthesis itself can influence proline metabolism (Figure S5). Previously P5CS1-GFP was localized in chloroplasts in salt-treated cells, supporting the assumption that proline biosynthesis can be associated with photosynthesis in stress conditions (Székely et al., 2008; Szabados and Savoure, 2010; Sharma et al., 2011). Glutamate-derived proline biosynthesis is a reductive metabolic pathway, which could be stimulated by photosynthetic NADPH in osmotically stressed Lotus corniculatus leaves (Diaz et al., 2005). Alternatively, chloroplast to nucleus retrograde signaling could be implicated in light control of P5CS1 and PDH1 genes (Gollan et al., 2015; Kleine and Leister, 2016). Deciphering the exact mechanism how light and photosynthesis regulates proline metabolism, however needs further investigation.

\section{MATERIALS AND METHODS}

\section{Plant Material and Growth Conditions}

Arabidopsis thaliana plants were either Col-0 or WS ecotype. The hy5hyh double mutant (Holm et al., 2002) has WS background. Basic conditions of plant growth were described before (Aleksza et al., 2017). Briefly: seeds were surface sterilized and germinated on $1 / 2 \mathrm{MS}$ culture medium containing $0.5 \%$ (W/V) sucrose. Plants were grown in vitro in growth chambers under $120 \mu \mathrm{E} \mathrm{m}^{-2}$ $\mathrm{s}^{-1}$ illumination (white light) using a $8 \mathrm{~h}$ light/16 h dark cycle, and $22^{\circ} \mathrm{C} / 18^{\circ} \mathrm{C}$ temperature cycle for 14 days.

For high-intensity light treatment 14-day-old plants were

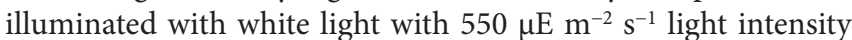
in growth chambers. For dark conditioning, 14-day-old plantlets were transferred to dark, and incubated in the absence of light for up to 5 days in the same conditions (medium, temperature). For subsequent light induction, plants were transferred to either white light (fluorescent cool white, $4200 \mathrm{~K}, 60 \mu \mathrm{E} \mathrm{m}^{-2} \mathrm{~s}^{-1}$ ), or monochromatic blue $\left(470 \mathrm{~nm}, 15 \mu \mathrm{E} \mathrm{m}^{-2} \mathrm{~s}^{-1}\right)$, red $(660 \mathrm{~nm}, 15 \mu \mathrm{E}$ $\left.\mathrm{m}^{-2} \mathrm{~s}^{-1}\right)$, or far-red $\left(730 \mathrm{~nm}, 5 \mu \mathrm{E} \mathrm{m} \mathrm{m}^{-2} \mathrm{~s}^{-1}\right)$ light, or kept in dark for up to three further days. The primary criteria for setting the fluence rate of light was to reach saturation of signaling cascades triggered by phytochrome and cryptochrome photoreceptors. The most studied light responses are saturated at the light intensities described above (Wolf et al., 2011; Adam et al., 2013). Dark-conditioned plants (including those kept in constant darkness) were transferred and handled under green light.

To induce proline accumulation, plants were cultured on the surface of thin-layer liquid culture medium $(10 \mathrm{ml}$ medium $/ 13 \mathrm{~cm}$ diameter Petri dish), using nylon mesh to prevent submergence. For stress, liquid media were supplemented with $150 \mathrm{mM} \mathrm{NaCl}$ or treated with $10 \mu \mathrm{M}$ ABA. Proline levels were determined in plants for up to 3 days as described.

\section{Proline Measurements}

Proline content was determined by the ninhydrin-based coloritmetric method as described (Abraham et al., 2010). Alternatively, a microtiter-scale colorimetric reaction was used, which was based on a recent paper (Lee et al., 2018) with some modifications. Plant material (approximately $50 \mathrm{mg}$ fresh 
weight/sample) was ground and $20 \mu \mathrm{l}$ of $1 \%$ (W/V) sulfosalicylic acid was added per mg FW tissue. After centrifugation at top speed $(15.000 \mathrm{rpm})$ for $5 \mathrm{~min}$ at $4^{\circ} \mathrm{C}$ in a microcentrifuge, the supernatant was removed and mixed with acidic ninhydrin $[1,25 \%(\mathrm{~W} / \mathrm{V})$ ninhydrin in $80 \%(\mathrm{~V} / \mathrm{V})$ acetic acid] in $1: 2$ ratio, and incubated at $95^{\circ} \mathrm{C}$ for $30 \mathrm{~min}$. The reaction was terminated on ice, and absorbance was measured at $510 \mathrm{~nm}$ in a plate reader (MULTISKAN GO, Thermo Scientific) using a 1:2 mixture of sulfosalicylic acid and acidic ninhydrin as reference. The system was calibrated with standard curves with known concentrations of proline. Anthocyanine accumulation was not visible in the plants after these treatments. Experiments were repeated three times and four to six replicates were used to determine proline levels in a treatment.

\section{Fast Chl A Fluorescence (OJIP) Measurements}

Fluorescence measurements were carried out at room temperature with a Handy-PEA instrument (Hansatech Instruments Ltd, UK). Plants were dark-adapted for $30 \mathrm{~min}$ and detached leaves were then placed in a modified Handy-PEA leaf clip. The leaf sample was illuminated with continuous red light $\left(3500 \mu \mathrm{E} \mathrm{m}^{-2} \mathrm{~s}^{-1}, 650\right.$ $\mathrm{nm}$ peak wavelength; the spectral half-width was $22 \mathrm{~nm}$; the light emitted by the LEDs is cut off at $700 \mathrm{~nm}$ by a NIR short-pass filter). The light was provided by an array of three light-emitting diodes focused on the sample surface. The first reliably measured point of the fluorescence transient is at $20 \mu \mathrm{s}$, which can be taken as $\mathrm{F}_{0}(\mathrm{O})$. The length of the measurements was $1 \mathrm{~s}$.

\section{DCMU Treatment}

Fourteen-day-old in vitro-grown plants (Col-0 ecotype) were transferred to $150 \mathrm{mM} \mathrm{NaCl}$ and/or sprayed with $50 \mu \mathrm{M}$ DCMU solution. OJIP fluorescence was measured 3 and $24 \mathrm{~h}$ after DCMU and salt treatments. Proline accumulation was measured 24,48 , and $72 \mathrm{~h}$ after DCMU treatment, whereas gene expression was measured after $24 \mathrm{~h}$.

\section{Gene Expression Studies}

To test transcript levels of selected genes, quantitative RT-PCR (qRT-PCR) was performed on cDNA templates obtained from total RNA samples. RNA isolation was performed with Nucleo Spin RNA isolation kit (Macherei-Nagel). Total RNA was DNase treated with TURBO DNA-free ${ }^{\mathrm{Tm}}$ Kit (Invitrogen by Thermo Fisher Scientific). First-strand cDNA synthesis of $1.5 \mu \mathrm{g}$ of total RNA was carried out with RevertAid M-MuLV Reverse Transcriptase (Fermentas), using random hexamers. Real-time PCR was carried out with the ABI 7900 Fast Real Time System (Applied Biosystems). The protocol in 45 cycles was $15 \mathrm{~s}$ at $95^{\circ} \mathrm{C}$, followed by $1 \mathrm{~min}$ at $60^{\circ} \mathrm{C}$. The specificity of the amplifications was verified using the ABI SDS software. Expression of the P5CS1 (AT2G39800) and PDH1 (AT3G30775) genes was monitored by qRT-PCR as described (Aleksza et al., 2017). Normalized transcript levels were calculated by the modified $2^{-\Delta \Delta \mathrm{Ct}}$ method using averages of actin2 (AT2G37620) and UBQ1 (AT3G52590) Ct values as reference (Livak and Schmittgen, 2001; Vandesompele et al., 2002). In relative expression data of the figures, reference was obtained on non-treated plants at the start of the experiment (e.g. dark-adapted plants, just before light and stress treatments). Statistical analysis was made on $2^{-\Delta \Delta C t}$ values of three replicates corresponding to cDNA templates and RNA samples isolated from three different Petri plates. Experiments were repeated at least twice. Primers used in qRT-PCR experiments are listed in Table S1.

The average amplification efficiencies of each primer pair used in the qRT-PCR experiments were derived from the slope of the amplification curve in the exponential phase of three different reactions from three different samples. The corresponding PCR efficiency was calculated according to the formula: $\mathrm{E}=10$ (1/ slope) (Svec et al., 2015). Each primer showed high amplification efficiency from 1.99 to 2.03 . Sequences of the PCR primers are available in Table $\mathbf{S 1}$.

\section{Chip Followed by Quantitative PCR}

The ChIP protocol by Werner Aufsatz (http://www.epigenomenoe.net/researchtools/protocol.php?protid=13) was applied with the following modifications. Fourteen-day-old hy 5 mutant plants expressing HY5-YFP fusion proteins from the HY5 promoter (Hajdu et al., 2018) were fixed in 1\% (V/V) formaldehyde solution. Chromatin samples were sonicated on ice six times for $10 \mathrm{~s}$ using a Vibra Cell sonicator (SONICS \& MATERIALS Inc., Danbury, CT, USA) at $10 \%$ power. Sonicated and diluted chromatin samples were pre-cleared by $20 \mu \mathrm{l}$ (bed volume) of binding control agarose beads (Chromotek GmbH, Germany) for $1 \mathrm{~h}$ at $4^{\circ} \mathrm{C}$. An aliquot of the pre-cleared chromatin solution was saved for the input sample and the rest of the material was precipitated using $12.5 \mu \mathrm{l}$ (bed volume) of GFP-Trap agarose beads (Chromotek GmbH, Germany) for $16 \mathrm{~h}$ at $4^{\circ} \mathrm{C}$. Precipitated chromatin was eluted from the beads, and along with the input sample, it was de-crosslinked and DNA was extracted using the Silica Bead DNA Gel Extraction Kit (Thermo Scientific). The final volume of purified DNA samples was about $45 \mu \mathrm{l}$. $1.5 \mu \mathrm{l}$ of the eluate was analyzed in qPCR reactions. Primers were designed to amplify genomic regions around the putative HY5 binding sites. Standard series were prepared from 10-fold dilutions of the input DNA samples. ChIP-related qPCR primers are listed in . ChIP data were analyzed and presented according to the "percent of input" method (Haring et al., 2007). Experiments were repeated three times.

\section{Electrophoretic Mobility Assay}

The pET28a vector carrying the full-length HY5 cDNA fragment (Hajdu et al., 2018) was introduced into Escherichia coli BL21 DE3 Rosetta cells (New England 513 Biolabs). Proteins were purified on His-Select Nickel affinity gel (SIGMA). $2 \mu \mathrm{g}$ of purified protein was incubated for $30 \mathrm{~min}$ with 2 pmol biotin-labeled DNA (respective P5CS1 and PDH1 oligonucleotide sequences are available in ). DNA fragments and complexes were separated in $4 \%(\mathrm{~W} / \mathrm{V})$ native polyacrylamide gel, then blotted to HyBond- $\mathrm{N}^{+}$ nucleic acid transfer membrane (Amersham). DNA fragments were crosslinked to the membrane with UV light (UV Stratalinker, 
Stratagene). DNA fragments were detected by an immune reaction with Streptavidin-conjugated horseradish-peroxidase (Thermo Scientific) using the LightShift Chemiluminescent EMSA Kit (Thermo Scientific). Signals were developed with a chemiluminescent substrate (Supersignal West-Thermo Scientific) and detected in Fusion FX western blot and gel documentation imaging device (Vilber). Experiments were repeated twice.

\section{Informatics, Statistical Analysis}

Promoter sequence analysis was performed with AthaMap tool (http://www.athamap.de). Oligonucleotides were designed and analyzed by IDT OligoAnalyzer (https://eu.idtdna.com/calc/ analyzer). Oligonucleotides used in this study are listed in Table S1.

Statistical analyses (one-way and two-way ANOVA, means comparisons by Tukey tests) were performed using the OriginPro 2018 software version 9.5 (OriginLab Corporation, Northampton, MA, USA). In case of one-way ANOVA the differences between means were determined Tukey test or by Duncan's multiple range test and labeled in all diagrams by different letters. When two-way ANOVA was used, the means comparison were made with Tukey test. Data were processed and in some experiments Diagrams were prepared with MS Excel 14.7.7, and figures were assembled with MS Powerpoint 14.7.7 and Adobe Photoshop CS5.1.

\section{REFERENCES}

Abbas, N., Maurya, J. P., Senapati, D., Gangappa, S. N., and Chattopadhyay, S. (2014). Arabidopsis CAM7 and HY5 physically interact and directly bind to the HY5 promoter to regulate its expression and thereby promote photomorphogenesis. Plant Cell 26, 1036-1052. doi: 10.1105/tpc.113.122515

Abraham, E., Rigo, G., Szekely, G., Nagy, R., Koncz, C., and Szabados, L. (2003). Light-dependent induction of proline biosynthesis by abscisic acid and salt stress is inhibited by brassinosteroid in Arabidopsis. Plant Mol. Biol. 51, 363372. doi: 10.1023/A:1022043000516

Abraham, E., Hourton-Cabassa, C., Erdei, L., and Szabados, L. (2010). Methods for determination of proline in plants. Methods Mol. Biol. 639, 317-331. doi: 10.1007/978-1-60761-702-0_20

Adam, E., Kircher, S., Liu, P., Merai, Z., Gonzalez-Schain, N., Horner, M., et al. (2013). Comparative functional analysis of full-length and N-terminal fragments of phytochrome C, D and E in red light-induced signaling. New Phytol. 200, 86-96. doi: 10.1111/nph.12364

Aleksza, D., Horvath, G. V., Sandor, G., and Szabados, L. (2017). Proline Accumulation Is Regulated by Transcription Factors Associated with Phosphate Starvation. Plant Physiol. 175, 555-567. doi: 10.1104/pp.17.00791

Ben Rejeb, K., Lefebvre-De Vos, D., Le Disquet, I., Leprince, A. S., Bordenave, M., Maldiney, R., et al. (2015). Hydrogen peroxide produced by NADPH oxidases increases proline accumulation during salt or mannitol stress in Arabidopsis thaliana. New Phytol. 208, 1138-1148. doi: 10.1111/nph.13550

Binkert, M., Kozma-Bognar, L., Terecskei, K., De Veylder, L., Nagy, F., and Ulm, R. (2014). UV-B-responsive association of the Arabidopsis bZIP transcription factor ELONGATED HYPOCOTYL5 with target genes, including its own promoter. Plant Cell 26, 4200-4213. doi: 10.1105/tpc.114.130716

Briggs, W. R., and Christie, J. M. (2002). Phototropins 1 and 2: versatile plant blue-light receptors. Trends Plant Sci. 7, 204-210. doi: 10.1016/ S1360-1385(02)02245-8

Casal, J. J., Candia, A. N., and Sellaro, R. (2014). Light perception and signalling by phytochrome A. J. Exp. Bot. 65, 2835-2845. doi: 10.1093/jxb/ert379

Chattopadhyay, S., Ang, L. H., Puente, P., Deng, X. W., and Wei, N. (1998). Arabidopsis bZIP protein HY5 directly interacts with light-responsive promoters in mediating light control of gene expression. Plant Cell 10, 673683. doi: $10.1105 /$ tpc. 10.5 .673

\section{AUTHOR CONTRIBUTIONS}

HK, DA, AIB, AH, AK, LZ, and ST performed the experiments. LK-B evaluated the results and corrected the manuscript. LS directed the research and wrote the manuscript.

\section{FUNDING}

This research was supported by NKFI Grants K128728, NN118089, and GINOP Project nos. 2.3.2-15-2016-00001 and 2.3.2-15-2016-00023. HK was supported by the Young Scientist Fellowship of the Hungarian Academy of Sciences.

\section{ACKNOWLEDGMENTS}

The authors are indebted to Erzsébet Fejes for reading and correcting the manuscript.

\section{SUPPLEMENTARY MATERIAL}

The Supplementary Material for this article can be found online at: https://www.frontiersin.org/articles/10.3389/fpls.2019.01584/ full\#supplementary-material

Chaves, I., Pokorny, R., Byrdin, M., Hoang, N., Ritz, T., Brettel, K., et al. (2011). The cryptochromes: blue light photoreceptors in plants and animals. Annu. Rev. Plant Biol. 62, 335-364. doi: 10.1146/annurev-arplant-042110-103759

Chen, H., Zhang, J., Neff, M. M., Hong, S. W., Zhang, H., Deng, X. W., et al. (2008). Integration of light and abscisic acid signaling during seed germination and early seedling development. Proc. Natl. Acad. Sci. U.S.A. 105, 4495-4500. doi: 10.1073/pnas.0710778105

Cluis, C. P., Mouchel, C. F., and Hardtke, C. S. (2004). The Arabidopsis transcription factor HY5 integrates light and hormone signaling pathways. Plant J. 38, 332 347. doi: 10.1111/j.1365-313X.2004.02052.x

D’alessandro, S., Ksas, B., and Havaux, M. (2018). Decoding beta-CyclocitralMediated Retrograde Signaling Reveals the Role of a Detoxification Response in Plant Tolerance to Photooxidative Stress. Plant Cell 30, 2495-2511. doi: $10.1105 /$ tpc. 18.00578

Delauney, A. J., and Verma, D. P. (1990). A soybean gene encoding delta 1-pyrroline5 -carboxylate reductase was isolated by functional complementation in Escherichia coli and is found to be osmoregulated. Mol. Gen. Genet. 221, 299305. doi: $10.1007 / \mathrm{BF} 00259392$

Delauney, A. J., and Verma, D. P. S. (1993). Proline biosynthesis and osmoregulation in plants. Plant J. 4, 215-223. doi: 10.1046/j.1365-313X.1993.04020215.x

Diaz, P., Borsani, O., Marquez, A., and Monza, J. (2005). Osmotically induced proline accumulation in Lotus corniculatus leaves is affected by light and nitrogen source. Plant Growth Regul. 46, 223-232. doi: 10.1007/s10725-005-0860-7

Dietrich, K., Weltmeier, F., Ehlert, A., Weiste, C., Stahl, M., Harter, K., et al. (2011). Heterodimers of the Arabidopsis transcription factors bZIP1 and bZIP53 reprogram amino acid metabolism during low energy stress. Plant Cell 23, 381-395. doi: 10.1105/tpc. 110.075390

Dubois, M., Claeys, H., Van Den Broeck, L., and Inze, D. (2017). Time of day determines Arabidopsis transcriptome and growth dynamics under mild drought. Plant Cell Environ. 40, 180-189. doi: 10.1111/pce.12809

Ehlert, A., Weltmeier, F., Wang, X., Mayer, C. S., Smeekens, S., VicenteCarbajosa, J., et al. (2006). Two-hybrid protein-protein interaction analysis in Arabidopsis protoplasts: establishment of a heterodimerization map of group C and group S bZIP transcription factors. Plant J. 46, 890-900. doi: 10.1111/j.1365-313X.2006.02731.x

Fabro, G., Kovacs, I., Pavet, V., Szabados, L., and Alvarez, M. E. (2004). Proline accumulation and AtP5CS2 gene activation are induced by plant-pathogen 
incompatible interactions in Arabidopsis. Mol. Plant Microbe Interact. 17, $343-$ 350. doi: 10.1094/MPMI.2004.17.4.343

Feng, X. J., Li, J. R., Qi, S. L., Lin, Q. F., Jin, J. B., and Hua, X. J. (2016). Light affects salt stress-induced transcriptional memory of P5CS1 in Arabidopsis. Proc. Natl. Acad. Sci. U.S.A. 113, E8335-E8343. doi: 10.1073/pnas.1610670114

Fernandez, A. P., and Strand, A. (2008). Retrograde signaling and plant stress: plastid signals initiate cellular stress responses. Curr. Opin. Plant Biol. 11, 509513. doi: 10.1016/j.pbi.2008.06.002

Fey, V., Wagner, R., Brautigam, K., Wirtz, M., Hell, R., Dietzmann, A., et al. (2005). Retrograde plastid redox signals in the expression of nuclear genes for chloroplast proteins of Arabidopsis thaliana. J. Biol. Chem. 280, 5318-5328. doi: 10.1074/jbc.M406358200

Fichman, Y., Gerdes, S. Y., Kovacs, H., Szabados, L., Zilberstein, A., and Csonka, L. N. (2015). Evolution of proline biosynthesis: enzymology, bioinformatics, genetics, and transcriptional regulation. Biol. Rev. Camb. Philos. Soc. 90, 1065-1099. doi: 10.1111/brv.12146

Franklin, K. A., and Quail, P. H. (2010). Phytochrome functions in Arabidopsis development. J. Exp. Bot. 61, 11-24. doi: 10.1093/jxb/erp304

Fu, Y., Ma, H., Chen, S., Gu, T., and Gong, J. (2018). Control of proline accumulation under drought via a novel pathway comprising the histone methylase CAU1 and the transcription factor ANAC055. J. Exp. Bot. 69, 579-588. doi: 10.1093/ $\mathrm{jxb} / \mathrm{erx} 419$

Fujita, Y., Fujita, M., Satoh, R., Maruyama, K., Parvez, M. M., Seki, M., et al. (2005). AREB1 Is a transcription activator of novel ABRE-dependent ABA signaling that enhances drought stress tolerance in Arabidopsis. Plant Cell 17, 34703488. doi: $10.1105 /$ tpc. 105.035659

Gangappa, S. N., and Botto, J. F. (2016). The Multifaceted Roles of HY5 in Plant Growth and Development. Mol. Plant 9, 1353-1365. doi: 10.1016/j.molp.2016.07.002

Gollan, P. J., Tikkanen, M., and Aro, E. M. (2015). Photosynthetic light reactions: integral to chloroplast retrograde signalling. Curr. Opin. Plant Biol. 27, 180191. doi: 10.1016/j.pbi.2015.07.006

Hajdu, A., Dobos, O., Domijan, M., Balint, B., Nagy, I., Nagy, F., et al. (2018). ELONGATED HYPOCOTYL 5 mediates blue light signalling to the Arabidopsis circadian clock. Plant J. 96, 1242-1254. doi: 10.1111/tpj.14106

Haring, M., Offermann, S., Danker, T., Horst, I., Peterhansel, C., and Stam, M. (2007). Chromatin immunoprecipitation: optimization, quantitative analysis and data normalization. Plant Methods 3, 11. doi: 10.1186/1746-4811-3-11

Hayashi, F., Ichino, T., Osanai, M., and Wada, K. (2000). Oscillation and regulation of proline content by P5CS and ProDH gene expressions in the light/dark cycles in Arabidopsis thaliana L. Plant Cell Physiol. 41, 1096-1101. doi: 10.1093/ $\mathrm{pcp} / \mathrm{pcd} 036$

Hildebrandt, T. M. (2018). Synthesis versus degradation: directions of amino acid metabolism during Arabidopsis abiotic stress response. Plant Mol. Biol. 98, 121-135. doi: 10.1007/s11103-018-0767-0

Hobo, T., Asada, M., Kowyama, Y., and Hattori, T. (1999). ACGT-containing abscisic acid response element (ABRE) and coupling element 3 (CE3) are functionally equivalent. Plant J. 19, 679-689. doi: 10.1046/j.1365-313x.1999.00565.x

Holm, M., Ma, L. G., Qu, L. J., and Deng, X. W. (2002). Two interacting bZIP proteins are direct targets of COP1-mediated control of light-dependent gene expression in Arabidopsis. Genes Dev. 16, 1247-1259. doi: 10.1101/gad.969702

Hu, C. A., Delauney, A. J., and Verma, D. P. (1992). A bifunctional enzyme (delta 1-pyrroline-5-carboxylate synthetase) catalyzes the first two steps in proline biosynthesis in plants. Proc. Natl. Acad. Sci. U.S.A. 89, 9354-9358. doi: 10.1073/ pnas.89.19.9354

Izawa, T., Foster, R., and Chua, N. H. (1993). Plant bZIP protein DNA binding specificity. J. Mol. Biol. 230, 1131-1144. doi: 10.1006/jmbi.1993.1230

Jimenez-Arias, D., Borges, A. A., Luis, J. C., Valdes, F., Sandalio, L. M., and Perez, J. A. (2015). Priming effect of menadione sodium bisulphite against salinity stress in Arabidopsis involves epigenetic changes in genes controlling proline metabolism. Environ. Exp. Bot. 120, 23-30. doi: 10.1016/j. envexpbot.2015.07.003

Joseph, M. P., Papdi, C., Kozma-Bognar, L., Nagy, I., Lopez-Carbonell, M., Rigo, G., et al. (2014). The Arabidopsis ZINC FINGER PROTEIN3 Interferes with Abscisic Acid and Light Signaling in Seed Germination and Plant Development. Plant Physiol. 165, 1203-1220. doi: 10.1104/pp.113.234294

Kami, C., Lorrain, S., Hornitschek, P., and Fankhauser, C. (2010). Light-regulated plant growth and development. Curr. Top. Dev. Biol. 91, 29-66. doi: 10.1016/ S0070-2153(10)91002-8
Kavi Kishor, P. B., and Sreenivasulu, N. (2014). Is proline accumulation per se correlated with stress tolerance or is proline homeostasis a more critical issue? Plant Cell Environ. 37, 300-311. doi: 10.1111/pce.12157

Kemble, A. R., and Macpherson, H. T. (1954). Liberation of amino acids in perennial ray grass during wilting. Biochem. J. 58, 46-59. doi: 10.1042/ bj0580046

Kesari, R., Lasky, J. R., Villamor, J. G., Des Marais, D. L., Chen, Y. J., Liu, T. W., et al. (2012). Intron-mediated alternative splicing of Arabidopsis P5CS1 and its association with natural variation in proline and climate adaptation. Proc. Natl. Acad. Sci. U.S.A. 109, 9197-9202. doi: 10.1073/pnas.1203433109

Kiyosue, T., Yoshiba, Y., Yamaguchi-Shinozaki, K., and Shinozaki, K. (1996). A nuclear gene encoding mitochondrial proline dehydrogenase, an enzyme involved in proline metabolism, is upregulated by proline but downregulated by dehydration in Arabidopsis. Plant Cell 8, 1323-1335. doi: 10.1105/ tpc.8.8.1323

Kleine, T., and Leister, D. (2016). Retrograde signaling: Organelles go networking. Biochim. Biophys. Acta 1857, 1313-1325. doi: 10.1016/j.bbabio.2016.03.017

Lee, J., He, K., Stolc, V., Lee, H., Figueroa, P., Gao, Y., et al. (2007). Analysis of transcription factor HY5 genomic binding sites revealed its hierarchical role in light regulation of development. Plant Cell 19, 731-749. doi: 10.1105/ tpc. 106.047688

Lee, M. R., Kim, C. S., Park, T., Choi, Y. S., and Lee, K. H. (2018). Optimization of the ninhydrin reaction and development of a multiwell plate-based highthroughput proline detection assay. Anal. Biochem. 556, 57-62. doi: 10.1016/j. ab.2018.06.022

Lehmann, S., Funck, D., Szabados, L., and Rentsch, D. (2010). Proline metabolism and transport in plant development. Amino Acids 39, 949-962. doi: 10.1007/ s00726-010-0525-3

Leivar, P., and Monte, E. (2014). PIFs: systems integrators in plant development. Plant Cell 26, 56-78. doi: 10.1105/tpc.113.120857

Li, J., Li, G., Gao, S., Martinez, C., He, G., Zhou, Z., et al. (2010). Arabidopsis transcription factor ELONGATED HYPOCOTYL5 plays a role in the feedback regulation of phytochrome A signaling. Plant Cell 22, 3634-3649. doi: 10.1105/ tpc. 110.075788

Livak, K. J., and Schmittgen, T. D. (2001). Analysis of relative gene expression data using real-time quantitative PCR and the 2(-Delta Delta C(T)) Method. Methods 25, 402-408. doi: 10.1006/meth.2001.1262

Muzammil, S., Shrestha, A., Dadshani, S., Pillen, K., Siddique, S., Leon, J., et al. (2018). An Ancestral Allele of Pyrroline-5-carboxylate synthase1 Promotes Proline Accumulation and Drought Adaptation in Cultivated Barley. Plant Physiol. 178, 771-782. doi: 10.1104/pp.18.00169

Parre, E., Ghars, M. A., Leprince, A. S., Thiery, L., Lefebvre, D., Bordenave, M., et al. (2007). Calcium signaling via phospholipase C is essential for proline accumulation upon ionic but not nonionic hyperosmotic stresses in Arabidopsis. Plant Physiol. 144, 503-512. doi: 10.1104/pp.106.095281

Pavlou, A., Jacques, J., Ahmadova, N., Mamedov, F., and Styring, S. (2018). The wavelength of the incident light determines the primary charge separation pathway in Photosystem II. Sci. Rep. 8, 2837. doi: 10.1038/s41598-018-21101-w

Per, T. S., Khan, N. A., Reddy, P. S., Masood, A., Hasanuzzaman, M., Khan, M. I. R., et al. (2017). Approaches in modulating proline metabolism in plants for salt and drought stress tolerance: Phytohormones, mineral nutrients and transgenics. Plant Physiol. Biochem. 115, 126-140. doi: 10.1016/j.plaphy.2017.03.018

Samach, A., Onouchi, H., Gold, S. E., Ditta, G. S., Schwarz-Sommer, Z., Yanofsky, M. F., et al. (2000). Distinct roles of CONSTANS target genes in reproductive development of Arabidopsis. Science 288, 1613-1616. doi: 10.1126/ science.288.5471.1613

Satoh, R., Nakashima, K., Seki, M., Shinozaki, K., and Yamaguchi-Shinozaki, K. (2002). ACTCAT, a novel cis-acting element for proline- and hypoosmolarityresponsive expression of the ProDH gene encoding proline dehydrogenase in Arabidopsis. Plant Physiol. 130, 709-719. doi: 10.1104/pp.009993

Satoh, R., Fujita, Y., Nakashima, K., Shinozaki, K., and Yamaguchi-Shinozaki, K. (2004). A novel subgroup of bZIP proteins functions as transcriptional activators in hypoosmolarity-responsive expression of the ProDH gene in Arabidopsis. Plant Cell Physiol. 45, 309-317. doi: 10.1093/pcp/pch036

Savouré, A., Hua, X. J., Bertauche, N., Van Montagu, M., and Verbruggen, N. (1997). Abscisic acid-independent and abscisic acid-dependent regulation of proline biosynthesis following cold and osmotic stresses in Arabidopsis thaliana. Mol. Gen. Genet. 254, 104-109. doi: 10.1007/s004380050397 
Schat, H., Sharma, S. S., and Vooijs, R. (1997). Heavy metal-induced accumulation of free proline in a metal-tolerant and a nontolerant ecotype of Silene vulgaris. Physiol. Plant 101, 477-482. doi: 10.1111/j.1399-3054.1997.tb01026.x

Servet, C., Ghelis, T., Richard, L., Zilberstein, A., and Savoure, A. (2012). Proline dehydrogenase: a key enzyme in controlling cellular homeostasis. Front. Biosci. (Landmark Ed) 17, 607-620. doi: 10.2741/3947

Sharma, S., and Verslues, P. E. (2010). Mechanisms independent of abscisic acid $(\mathrm{ABA})$ or proline feedback have a predominant role in transcriptional regulation of proline metabolism during low water potential and stress recovery. Plant Cell Environ. 33, 1838-1851. doi: 10.1111/j.1365-3040.2010.02188.x

Sharma, S., Villamor, J. G., and Verslues, P. E. (2011). Essential role of tissuespecific proline synthesis and catabolism in growth and redox balance at low water potential. Plant Physiol. 157, 292-304. doi: 10.1104/pp.111.183210

Sheerin, D. J., Menon, C., Zur Oven-Krockhaus, S., Enderle, B., Zhu, L., Johnen, P., et al. (2015). Light-activated phytochrome A and B interact with members of the SPA family to promote photomorphogenesis in Arabidopsis by reorganizing the COP1/SPA complex. Plant Cell 27, 189-201. doi: 10.1105/tpc.114.134775

Singh, A., Ram, H., Abbas, N., and Chattopadhyay, S. (2012). Molecular interactions of GBF1 with HY5 and HYH proteins during light-mediated seedling development in Arabidopsis thaliana. J. Biol. Chem. 287, 25995-26009. doi: 10.1074/jbc.M111.333906

Strizhov, N., Abraham, E., Okresz, L., Blickling, S., Zilberstein, A., Schell, J., et al. (1997). Differential expression of two P5CS genes controlling proline accumulation during salt-stress requires $\mathrm{ABA}$ and is regulated by ABA1, ABI1 and AXR2 in Arabidopsis. Plant J. 12, 557-569. doi: 10.1046/j.1365-313X.1997.00537.x

Svec, D., Tichopad, A., Novosadova, V., Pfaffl, M. W., and Kubista, M. (2015). How good is a PCR efficiency estimate: Recommendations for precise and robust qPCR efficiency assessments. Biomol. Detect. Quantif. 3, 9-16. doi: 10.1016/j. bdq.2015.01.005

Szabados, L., and Savoure, A. (2010). Proline: a multifunctional amino acid. Trends Plant Sci. 15, 89-97. doi: 10.1016/j.tplants.2009.11.009

Székely, G., Ábrahám, E., Cséplö, A., Rigó, G., Zsigmond, L., Csiszár, J., et al. (2008). Duplicated P5CS genes of Arabidopsis play distinct roles in stress regulation and developmental control of proline biosynthesis. Plant J. 53, 11-28. doi: 10.1111/j.1365-313X.2007.03318.x

Thapper, A., Mamedov, F., Mokvist, F., Hammarstrom, L., and Styring, S. (2009). Defining the far-red limit of photosystem II in spinach. Plant Cell 21, 23912401. doi: 10.1105/tpc.108.064154

Thiery, L., Leprince, A. S., Lefebvre, D., Ghars, M. A., Debarbieux, E., and Savoure, A. (2004). Phospholipase D is a negative regulator of prolinebiosynthesis in Arabidopsis thaliana. J. Biol. Chem. 279, 14812-14818. doi: 10.1074/jbc.M308456200

Toledo-Ortiz, G., Johansson, H., Lee, K. P., Bou-Torrent, J., Stewart, K., Steel, G., et al. (2014). The HY5-PIF regulatory module coordinates light and temperature control of photosynthetic gene transcription. PloS Genet. 10, e1004416. doi: 10.1371/journal.pgen.1004416

Tóth, S. Z., Schansker, G., and Strasser, R. J. (2007). A non-invasive method for the determination of the redox state of the PQ-pool. Photosynthesis Res. 93, 193-203. doi: 10.1007/s11120-007-9179-8
Vandesompele, J., De Preter, K., Pattyn, F., Poppe, B., Van Roy, N., De Paepe, A., et al. (2002). Accurate normalization of real-time quantitative RT-PCR data by geometric averaging of multiple internal control genes. Genome Biol. 3, RESEARCH0034. doi: 10.1186/gb-2002-3-7-research0034

Verslues, P. E., and Sharma, S. (2010). Proline metabolism and its implications for plant-environment interaction. Arabidopsis Book 8, e0140. doi: 10.1199/ tab. 0140

Weltmeier, F., Ehlert, A., Mayer, C. S., Dietrich, K., Wang, X., Schutze, K., et al. (2006). Combinatorial control of Arabidopsis proline dehydrogenase transcription by specific heterodimerisation of bZIP transcription factors. EMBO J. 25, 3133-3143. doi: 10.1038/sj.emboj.7601206

Williams, M. E., Foster, R., and Chua, N. H. (1992). Sequences flanking the hexameric G-box core CACGTG affect the specificity of protein binding. Plant Cell 4, 485-496. doi: 10.1105/tpc.4.4.485

Wind, J. J., Peviani, A., Snel, B., Hanson, J., and Smeekens, S. C. (2012). ABI4: versatile activator and repressor. Trends Plant Sci. 18, 125-132. doi: 10.1016/j. tplants.2012.10.004

Wolf, I., Kircher, S., Fejes, E., Kozma-Bognar, L., Schafer, E., Nagy, F., et al. (2011). Light-regulated nuclear import and degradation of Arabidopsis phytochrome-A N-terminal fragments. Plant Cell Physiol. 52, 361-372. doi: $10.1093 /$ pcp/pcq194

Yang, S. L., Lan, S. S., and Gong, M. (2009). Hydrogen peroxide-induced proline and metabolic pathway of its accumulation in maize seedlings. J. Plant Physiol. 166, 1694-1699. doi: 10.1016/j.jplph.2009.04.006

Yoshida, T., Fujita, Y., Sayama, H., Kidokoro, S., Maruyama, K., Mizoi, J., et al. (2010). AREB1, AREB2, and ABF3 are master transcription factors that cooperatively regulate ABRE-dependent ABA signaling involved in drought stress tolerance and require ABA for full activation. Plant J. 61, 672-685. doi: 10.1111/j.1365-313X.2009.04092.x

Zarattini, M., and Forlani, G. (2017). Toward Unveiling the Mechanisms for Transcriptional Regulation of Proline Biosynthesis in the Plant Cell Response to Biotic and Abiotic Stress Conditions. Front. Plant Sci. 8, 927. doi: 10.3389/ fpls.2017.00927

Zhang, H., He, H., Wang, X., Wang, X., Yang, X., Li, L., et al. (2011). Genome-wide mapping of the HY5-mediated gene networks in Arabidopsis that involve both transcriptional and post-transcriptional regulation. Plant J. 65, 346-358. doi: $10.1111 / j .1365-313 X .2010 .04426 . x$

Conflict of Interest: The authors declare that the research was conducted in the absence of any commercial or financial relationships that could be construed as a potential conflict of interest.

Copyright (® 2019 Kovács, Aleksza, Baba, Hajdu, Király, Zsigmond, Tóth, KozmaBognár and Szabados. This is an open-access article distributed under the terms of the Creative Commons Attribution License (CC BY). The use, distribution or reproduction in other forums is permitted, provided the original author(s) and the copyright owner(s) are credited and that the original publication in this journal is cited, in accordance with accepted academic practice. No use, distribution or reproduction is permitted which does not comply with these terms. 